\title{
Low expression of antigen-presenting and costimulatory molecules by lung cells from tuberculosis patients
}

V.C.S. Flores-Batista ${ }^{1}$, N. Boechat ${ }^{1}$, P.M. Lago ${ }^{1}$, L.C. Lazzarini ${ }^{1}$, L.R. Pessanha ${ }^{1}$, A.S. Almeida ${ }^{1}$, T.T. Mafort ${ }^{1}$, A.L. Kritski ${ }^{1}$, J.L. $\mathrm{Ho}^{2}$ and J.R. Lapa-e-Silva ${ }^{1,2}$

\author{
${ }^{1}$ Laboratório Multidisciplinar de Pesquisa, Instituto de Doenças do Tórax, \\ Hospital Universitário Clementino Fraga Filho, Universidade Federal do Rio de Janeiro, \\ Rio de Janeiro, RJ, Brasil \\ ${ }^{2}$ Division of International Medicine and Infectious Diseases, \\ Weill Medical College of Cornell University, New York, NY, USA
}

\section{Correspondence \\ J.R. Lapa-e-Silva \\ Laboratório Multidisciplinar de Pesquisa \\ Hospital Universitário Clementino Fraga Filho \\ Instituto de Doenças do Tórax, UFRJ Av. Brigadeiro Trompovski, $\mathrm{s} / \mathrm{n}$ 20541-590 Rio de Janeiro, RJ Brasil \\ Fax: +55-21-2290-3520 \\ E-mail: jrlapa.ntg@terra.com.br}

Research supported by Fogarty/NIH 3 D43 TW000018-16S3 and 5 U2R TW006883-02 grants, Instituto Millenium/CNPq (No. 480269/2003-3) and PRONEX/FAPERJ/CNPq (No. E-26/171.203/2003).

Received October 20, 2006 Accepted May 9, 2007 ...................

\begin{abstract}
Costimulatory and antigen-presenting molecules are essential to the initiation of $\mathrm{T}$ cell immunity to mycobacteria. The present study analyzed by immunocytochemistry, using monoclonal antibodies and alkaline phosphatase-anti-alkaline phosphatase method, the frequency of costimulatory (CD86, CD40, CD40L, CD28, and CD152) and antigen-presenting (MHC class II and CD1) molecules expression on human lung cells recovered by sputum induction from tuberculosis (TB) patients $(\mathrm{N}=22)$ and non- $\mathrm{TB}$ controls $(\mathrm{N}=17)$. $\mathrm{TB}$ cases showed a statistically significant lower percentage of HLA-DR+ cells than control subjects $(21.9 \pm 4.2$ vs $50.0 \pm 7.2 \%, \mathrm{P}<0.001)$, even though similar proportions of TB cases (18/22) and control subjects (16/17, P $=0.36)$ had HLA-DR-positive-stained cells. In addition, fewer TB cases (10/22) compared to control subjects (16/17) possessed CD86expressing cells $(\mathrm{P}=0.04$; OR: $0.05 ; 95 \% \mathrm{CI}=0.00-0.51)$, and $\mathrm{TB}$ cases expressed a lower percentage of $\mathrm{CD} 86+$ cells $(\mathrm{P}=0.04)$. Moreover, TB patients with clinically limited disease $(\leq 1$ lobe $)$ on chest X-ray exhibited a lower percentage of CD86-bearing cells compared to patients with more extensive lung disease ( $>1$ lobe) $(\mathrm{P}=$ 0.02). The lower expression by lung cells from TB patients of HLADR and CD86, molecules involved in antigen presentation and activation of $\mathrm{T}$ cells, may minimize $\mathrm{T}$ cell recognition of Mycobacterium tuberculosis, fostering an immune dysfunctional state and active TB.
\end{abstract}

Key words

- Tuberculosis

- Costimulatory molecules

- CD86

- MHC class II

- HLA-DR

\section{Introduction}

One of the most intriguing aspects of tuberculosis (TB), a disease that kills over two million people every year (1), is the finding of a functionally down-modulated lung state despite a demonstrable Th1 type lung immune response $(2,3)$. TB is also known to impair delayed type hypersensitivity reactivity to the tuberculin skin test and to induce diminished peripheral blood $\mathrm{T}$ cell proliferation and reduced IL-2 production (4-6). Proliferation and activation of T cells are initiated by binding of the CD3/TCR complex to costimulatory signals provided by the B7:CD28 family, CD80 (B7.1) and 
CD86 (B7.2), and antigen peptides presented on MHC class II molecules (for a recent review, see Ref. 7). Specifically, development of Mycobacterium tuberculosis-specific $\mathrm{T}$ cells and interferon- $\gamma(\mathrm{IFN}-\gamma)$ involves binding of MHC class II molecule/ mycobacterial antigen peptide to $\mathrm{T}$ cell receptors, along with CD80/86 coupling to CD28 and CD40 coupling to CD40L (8). The ability to evade or suppress the host's immune response is a property of several pathogens, indicating that an immune evasion mechanism provides an advantage for the spreading and the persistence of infection (9). Clinical and experimental data support the concept that active TB is dependent in part on a "shutting-off" of the host's proinflammatory immune response, with decreased production of IFN- $\gamma$ and interleukin 12 (IL-12) concomitant with increased production of immunosuppressive cytokines, IL-10 and TGF- $\beta(2,3,10,11)$, that may alter the interaction of antigen-presenting cells with T cells. IL-10 was shown to diminish costimulatory molecules in vitro upon $M$. tuberculosis infection of monocytes-macrophages from healthy individuals (8). Neutralizing endogenous IL-10 resulted in upregulation of $\mathrm{CD} 86$ expression on target cells from TB patients (8). In vitro infection of human macrophages with $M$. bovis BCG and M. tuberculosis attenuated MHC class II surface expression (12). Moreover, treatment of the infected macrophages with neutralizing anti-IL-10 antibodies restored the expression of class II molecules on cell surface (12).

Prior study from our group demonstrated increased levels of IL-10 and TGF- $\beta$ in the bronchoalveolar fluid, as well as increased co-expression of TGF- $\beta$ receptors I and II by lung cells from TB patients (2). We also showed that a culture filtrate protein of $M$. tuberculosis (designated as CFP32) was present in the sputum of TB patients whose level positively correlated with the amounts of IL10 but not with IFN- $\gamma(3)$. Moreover CFP32 is a potent inducer of IL-10 production by human monocytes in vitro (Huard RC, Weill Medical College of Cornell University, New York, USA, personal communication). The promotion of IL-10 secretion by $M$. tuberculosis may ultimately function as an evasion strategy, favoring the development of a relatively down-modulated lung milieu. In summary, it is possible that by direct M. tuberculosis infection or by indirect paracrine immunosuppressive cytokines, $M$. tuberculosis will foster lower expression of surface costimulatory and antigen-presenting molecules.

Therefore, we investigated whether active TB is also associated with diminished expression of costimulatory (CD86, CD40, CD150 (CD40L), CD28, and CD152 (CTL$4)$ ), and antigen-presenting (MHC class II DR and CD1a) molecules by lung cells and, if this is the case, uncontrolled proliferation of M. tuberculosis and active disease are favored. We compared lung cells recovered from patients presenting active pulmonary $\mathrm{TB}$, from patients with pulmonary diseases other than TB and from healthy control individuals.

\section{Patients and Methods}

\section{Study design and ethics}

A case-control study was performed. Ambulatory patients were recruited at the Chest Clinics of the Institute of Thoracic Diseases, Clementino Fraga Filho University Hospital, a Brazilian national reference center for TB and AIDS. From June 1998 to March 200140 subjects (TB, N = 23; non$\mathrm{TB}, \mathrm{N}=17$ ) were enrolled in the present study. Patients were referred to the pulmonary services for TB diagnosis by induced sputum because of epidemiological and clinical factors, abnormal roentgenograms, inability to produce spontaneous sputum for microbiological diagnosis, or having a negative Ziehl-Nielsen staining for acid-fast ba- 
cilli in spontaneous sputum. Excluded were patients with HIV seropositivity, diabetes mellitus, cardiac failure, liver failure, renal failure, chronic obstructive pulmonary disease, current use of corticosteroids, immunodepressive agents, or anti-tuberculous therapy for more than 1 week. Twenty-three patients with culture-proven pulmonary TB were enrolled; 1 TB patient was excluded from the final data analysis due to positive HIV-1 serology. Thus, the final study group consisted of 22 patients, 13 males, aged 17 to 58 years (mean: $33.91 \pm 2.2$ years). A control group of 17 subjects ( 9 males, 19-70 years old (mean $35.82 \pm 4.5)$ ) composed of healthy volunteers (hospital staff, students and others, $N=10$ ) and patients with nonTB pulmonary diseases (respiratory tract infections, $\mathrm{N}=6$, and lung cancer, $\mathrm{N}=1$ ) was also studied. All participants agreed to take part in the study and signed informed consent forms. The University Hospital Institutional Revision Board approved the study.

\section{Clinical, radiological, and bacteriological data}

After signing informed consent, the subjects answered a standardized questionnaire on symptoms and signs related to their conditions, were submitted to a chest X-ray, blood tests, including HIV serology, and sputum induction.

\section{Sputum induction and processing}

Sputum was induced as described by Pin et al (12). Briefly, patients were pretreated with $200 \mu \mathrm{g}$ inhaled salbutamol to inhibit airway constriction. Hypertonic saline (3\%) aerosol was administered to patients and healthy controls during two periods of 10 min each using an ultrasonic nebulizer (De Vilbiss, London, UK). After each inhalation period, subjects were asked to blow their nose, rinse their mouth, swallow water (to minimize contamination with postnasal dripping and saliva) and finally, to expectorate into a sterile container. At the end of the procedure, peak flow measurement was performed and any fall in peak flow was recorded. In case of bronchospasm the nebulization was interrupted and bronchodilator drugs were administered. The resulting sputum was processed within $2 \mathrm{~h}$. Half of the sputum was sent to the Mycobacteriology Laboratory for routine diagnosis: ZiehlNielsen staining, microscopic examination for acid-fast bacilli and culture in Lowenstein Jensen medium. All positive cultures were tested by biochemical methods and drug sensitivity was determined by the proportionate method (13). For the second sputum aliquot, the dense and viscid portions free of salivary contamination were placed in a 15$\mathrm{mL}$ conical polystyrene tube (Falcon 2097, Becton Dickinson, Franklin Lakes, NJ, USA), mixed and treated with a $0.1 \%$ dithiothreitol in distilled water (Sigma, St. Louis, MO, USA) to dissociate disulfide bonds in mucus. This mixture was vortexed for $15 \mathrm{~s}$ and further mixed by gentle aspiration in and out with a Pasteur pipette. The contents in conical tubes were rocked for $15 \mathrm{~min}$ in a bench rocker to which 4 volumes of phosphatebuffered saline were added, and further rocked for $5 \mathrm{~min}$. The cell suspension was centrifuged $\left(1500 \mathrm{rpm}, 20 \mathrm{~min}\right.$ at $4^{\circ} \mathrm{C}$; Becton Dickinson) and the cell pellet was further washed twice in phosphate-buffered saline each time after cell resupension. Total leukocytes were counted with a Neubauer hemocytometer. Cell viability was determined by Trypan blue exclusion. The total recovered cells numbered from $5.3 \times 10^{6}$ to $1.4 \times 10^{7}$ and viability was $>80 \%$. The lung cells were suspended at $1.0 \times 10^{6}$ per mL. Cytospins containing $\geq 5 \times 10^{5}$ were prepared on slides coated with poly-L-lysine (Sigma), by centrifugation (Cytospin 3, Shandon, Astmoor, UK), and air dried. Differential cell count of at least 200 nonsquamous cells was performed on slides stained with May-Grünwald-Giemsa (Laborclin, Campinas, SP, Brazil). 


\section{Immunocytochemistry}

Cytospins were fixed in cold acetone for $10 \mathrm{~min}$, air dried at room temperature, wrapped in plastic film, and kept at $-20^{\circ} \mathrm{C}$ prior to use. Alkaline phosphatase-anti-alkaline phosphatase staining was performed using the following primary monoclonal antibodies: CD1a (dendritic cells), HLA-DR (MHC class II) both from PharMingen/ Becton Dickinson (Franklin Lakes, NJ, USA), CD86 (B7.2, costimulatory molecule), CD40L (CD154, costimulatory molecule), both from Dako AS (Glostrup, Norway), CD40 (costimulatory molecule), CD152 (CTLA-4, costimulatory molecule), both from Santa Cruz Biotechnology (Santa Cruz, CA, USA), CD28 (costimulatory molecule), from R\&D Systems (Minneapolis, MN, USA). After 1-h incubation, the slides were washed in Tris-buffered saline, followed by anti-rat immunoglobulin rabbit Ig (D455, Dako A/S, Glostrup, Denmark) and by alkaline phosphatase-streptavidin AP (D0396, Dako). The reaction was developed with the substrates Fast Red TR and naphthol AS MX

Table 1. Demographic, clinical, and radiologic features of tuberculosis cases and controls.

\begin{tabular}{lccc}
\hline Characteristics & $\begin{array}{c}\text { Tuberculosis } \\
\text { cases }(\mathrm{N}=22)\end{array}$ & $\begin{array}{c}\text { Controls } \\
(\mathrm{N}=17)\end{array}$ & OR (95\%Cl) \\
\hline Mean age & $33.91 \pm 2.2$ & $35.82 \pm 4.5$ & \\
Males & $13(59.1 \%)$ & $9(52.9 \%)$ & $1.28(0.30-5.59)$ \\
Smokers & $8(36.4 \%)$ & $4(23.5 \%)$ & $1.86(0.37-9.73)$ \\
Alcoholism & $1(4.5 \%)$ & $2(11.8 \%)$ & $0.38(0.01-6.17)$ \\
Asthma/rhinitis & $1(4.5 \%)^{\star}$ & $6(35.3 \%)$ & $0.00(0.09-0.92)$ \\
Previous tuberculosis & $4(18.2 \%)$ & $3(17.6 \%)$ & $1.04(0.16-7.19)$ \\
Duration of symptoms in weeks & $11.3 \pm 2.6$ & $5.3 \pm 3.1$ & $1.0(-2.1-14.1)$ \\
Extension <1 lobe & $11(50 \%)$ & $4(18.2 \%)$ & $3.25(0.67-16.82)$ \\
Extension >1 lobe & $10(45.5 \%)^{*}$ & $1(4.5 \%)$ & $13.33(1.49-118.9)$ \\
Cavitary disease & $9(40.9 \%)^{*}$ & $0(0 \%)$ & $\mathrm{NA}$ \\
Non-cavitary disease & $12(54.5 \%)$ & $4(18.2 \%)$ & $3.90(0.80-20.33)$ \\
Low mycobacterial load & $9(40.9 \%)$ & $\mathrm{NA}$ & $\mathrm{NA}$ \\
High mycobacterial load & $10(45.5 \%)$ & $\mathrm{NA}$ & $\mathrm{NA}$ \\
& & &
\end{tabular}

Data are reported as mean \pm SEM or number with percent in parentheses. Extension = number of pulmonary lobes affected by the disease; cavitary tuberculosis = lung cavitation on the chest $\mathrm{X}$-ray; $\mathrm{OR}=$ odds ratio; $95 \% \mathrm{Cl}=95 \%$ confidence interval; $\mathrm{NA}=$ not applicable.

${ }^{*} \mathrm{P}<0.05$ compared to controls (Student $t$-test). phosphate (Sigma) and light hematoxylin counterstaining. Negative controls were generated by substituting the primary antibodies for Tris-buffered saline. Slides were stained, coded and read in a "blind" fashion. Positively stained cells (pink to red color) were counted in at least 10 fields at a magnification of 400X, with enumeration of $\geq 200$ cells. The results are reported as number of positive cells per total number of macrophages or total number of cells counted on the slide.

\section{Statistical analysis}

Statistical analysis was performed with the GraphPad Prism 4 software (GraphPad Software, Inc., San Diego, CA, USA). The Student $t$-test was used for comparisons between TB cases and controls for parametric data and the Mann-Whitney test for nonparametric analysis. The Fisher exact test was used when the expected value was less than 5. Level of significance was 5\%.

\section{Results}

Twenty-two pulmonary TB cases and 17 non-TB controls were studied (healthy volunteers, $\mathrm{N}=10$, and patients with non-TB pulmonary diseases (respiratory tract infections that were cured by short-course antibiotics, $\mathrm{N}=6$, and primary lung cancer, $\mathrm{N}=$ 1). The demographic and clinical characteristics of the case and control groups were similar except for a past history of asthma and allergy (Table 1). Table 1 also describes the radiologic and bacteriologic findings. TB cases were further subdivided into "limited disease" or "extensive disease" defined as lung involvement of less than one lobe or more than one lobe, respectively, on chest $\mathrm{X}$-ray at first medical visit; as having cavitary or non-cavitary disease by the presence of cavitation, and as having low or high mycobacterial load (defined as $\leq 20$ colonies or $>20$ colonies in the culture media). 
Lung cells obtained by the induced sputum technique for evaluation of immune cell markers

The volume of induced sputum, cell yield and differential cell counts are described in Table 2. Significantly lower percentages of macrophages and higher percentages of neutrophils were present in sputum from TB cases than in controls. The cell yield and low percentage of squamous cells suggest the utility of induced sputum for studying lung immune response in pulmonary TB.

Expression of antigen-presenting molecules revealed that MHC class II HLA-DR are diminished in tuberculosis patients

Figure 1 shows the percent distribution of positive cells in the two study groups related to total cell or to total macrophage numbers. A statistically significant lower percentage of cells possessing HLA-DR was found for both total lung cells and lung macrophages among TB cases. However, the proportions of cases and controls having HLA-DR-positive cells were similar, 18 of 22 among TB cases and 16 of 17 among control subjects. Further analysis of HLADR expression in TB cases by extent of disease (limited versus extensive ( $\geq 1$ lobe)), by lung cavitation, and by mycobacterial load on culture plates $(<20$ or $\geq 20)$ showed no statistically significant differences. In a similar analysis, CD1a expression was similar between TB cases and controls (Table 3).

Expression of the costimulatory molecule CD86 (B7.2) is decreased in tuberculosis patients

Fewer TB patients expressed detectable CD86-positive cells, 10 of 22 versus 16 of 17 control subjects $(\mathrm{P}<0.042)$. Figure 2 shows the expression of CD86 by total lung cells or by macrophages. TB cases showed a statistically significant lower CD86 expres-
Table 2. Characteristics of the induced sputum.

\begin{tabular}{lcc}
\hline Characteristics & Tuberculosis cases $(\mathrm{N}=22)$ & Controls $(\mathrm{N}=17)$ \\
\hline Volume $(\mathrm{mL})$ & $3.045 \pm 0.2770$ & $3.324 \pm 0.2906$ \\
Cells per $\mathrm{mL} \times 10^{6}$ & $7.370 \pm 1.929$ & $11.10 \pm 3.389$ \\
Macrophages $(\%)$ & $67.78 \pm 4.723 \%^{*}$ & $83.59 \pm 3.198 \%$ \\
Lymphocytes (\%) & $0.246 \pm 0.089 \%$ & $0.365 \pm 0.172 \%$ \\
Neutrophils (\%) & $29.06 \pm 4.99 \%^{*}$ & $15.26 \pm 4.35 \%$ \\
Eosinophils (\%) & $0.086 \pm 0.086 \%$ & $0.831 \pm 0.43 \%$ \\
Epithelial cells $(\%)$ & $2.823 \pm 0.89 \%$ & $3.094 \pm 0.929 \%$
\end{tabular}

Data are reported as means \pm SEM.

${ }^{*} \mathrm{P}<0.05$ compared to controls (Student $t$-test).

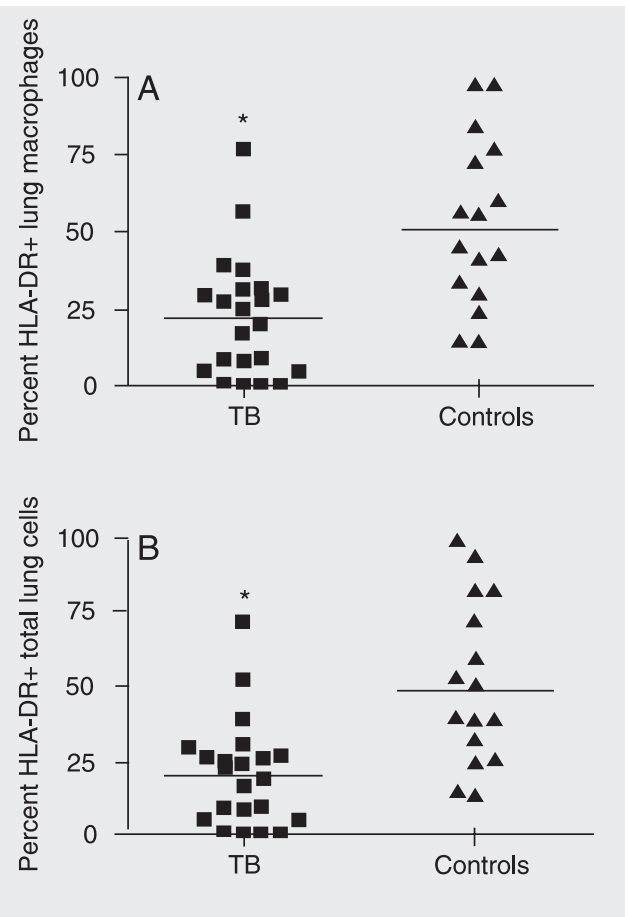

Figure 1. HLA class II DR expression by total lung cells or macrophages from tuberculosis (TB) cases and non-TB controls. The horizontal lines are the means. $A$ Percentage of macrophages, and $B$, percentage of total lung cells expressing HLA-DR. Cells from induced sputum were prepared from TB cases $(\mathrm{N}=22)$ and nonTB controls ( $N=17)$ consisting of healthy volunteers $(N=10)$, nonTB pulmonary infection $(\mathrm{N}=6)$, and a patient with lung cancer ( $\mathrm{N}$ $=1) .{ }^{*} \mathrm{P}<0.05$ compared to controls (Student $t$-test). One result for the controls was equal to zero and is not shown.

Table 3. CD1a and costimulatory molecules.

\begin{tabular}{lcccc}
\hline Markers & $\begin{array}{c}\text { Positive staining } \\
\text { in tuberculosis } \\
(\mathrm{N}=22)\end{array}$ & $\begin{array}{c}\text { Positive staining } \\
\text { in controls } \\
(\mathrm{N}=17)\end{array}$ & $\begin{array}{c}\text { \% Positive cells } \\
\text { in tuberculosis } \\
(\mathrm{N}=22)\end{array}$ & $\begin{array}{c}\% \text { Positive cells } \\
\text { in controls } \\
(\mathrm{N}=17)\end{array}$ \\
\hline CD1a & 3 & 2 & $0.80 \pm 0.49 \%$ & $0.23 \pm 0.19 \%$ \\
CD40 & 10 & 12 & $4.03 \pm 1.17 \%$ & $4.78 \pm 1.3 \%$ \\
CD40L & 3 & 4 & $0.22 \pm 0.14 \%$ & $0.82 \pm 0.41 \%$ \\
CD28 & 5 & 3 & $2.55 \pm 1.19 \%$ & $1.03 \pm 0.53 \%$ \\
CD152 & 2 & 2 & $0.88 \pm 0.76 \%$ & $0.29 \pm 0.24 \%$ \\
\hline
\end{tabular}

$\mathrm{CD}=$ clusters of differentiation . 
sion as determined by total lung cells or by lung macrophages compared to controls. TB cases were further subdivided by disease severity. Figure $2 \mathrm{C}$ shows that patients with limited TB $(<1$ lobe) exhibited a significantly lower CD86 expression by lung macrophages $(\mathrm{P}=0.021)$. However, no statistically significant difference was observed for CD86 expression when TB cases were analyzed by presence of cavitary disease or by bacillary load. CD80 could not be evaluated because of an insufficient number of slides containing cytopreparation of cells from TB patients and controls. In contrast to CD86, other costimulatory molecules evaluated, CD40, CD150 (CD40L), CD28 and CD152 (CTL-4), failed to show differences between TB cases and controls (Table 3 ).

\section{Discussion}

Experimental models of $M$. tuberculosis infection have advanced our understanding of the pathogenesis of TB, shedding light on host resistance/susceptibility mechanisms, mycobacterial virulence factors and evasion
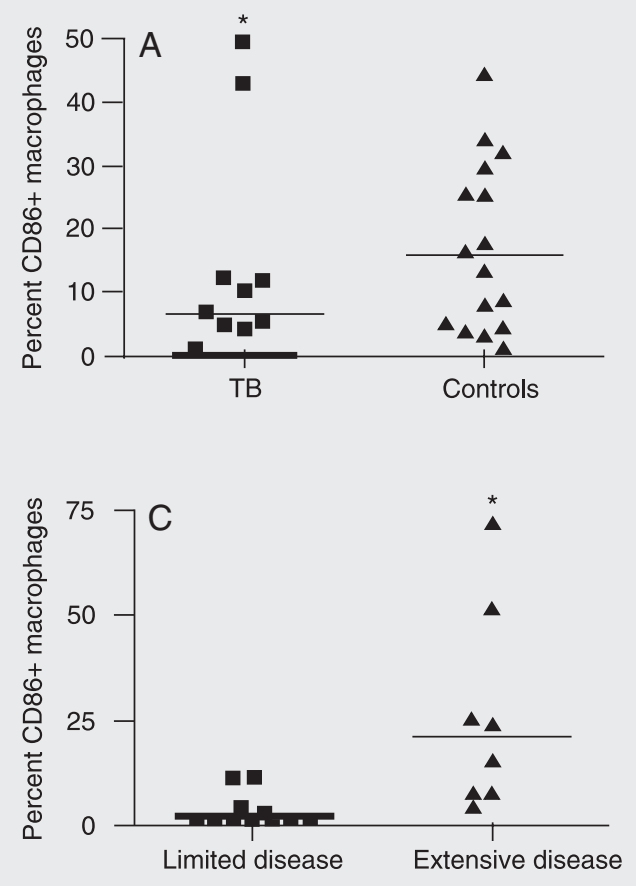

strategies. Nevertheless, neither in vivo nor in vitro animal models of $\mathrm{TB}$ mimic human disease. Therefore, understanding TB still requires studies on human or non-human primates. It is noteworthy that the majority of the studies conducted on humans have used cells from peripheral blood or pleural effusion. These studies may not mirror the immune response in the lung, the site of direct host and $M$. tuberculosis interaction in over $80 \%$ of TB cases.

Investigation of the lung compartment is hampered by the relative inaccessibility of the lung parenchyma. Bronchoalveolar lavage, considered to be the gold standard for these analyses, is expensive and invasive, and is associated with occasional serious adverse events. Despite these serious limitations, our group has extensively used bronchoalveolar lavage to investigate lung immune responses in human TB $(2,14,15)$. Alternatively, induced sputum has proven ability to enhance the culture diagnosis of pulmonary TB even in the case of pleural disease $(16,17)$. Previous studies using induced sputum have suggested its usefulness in the

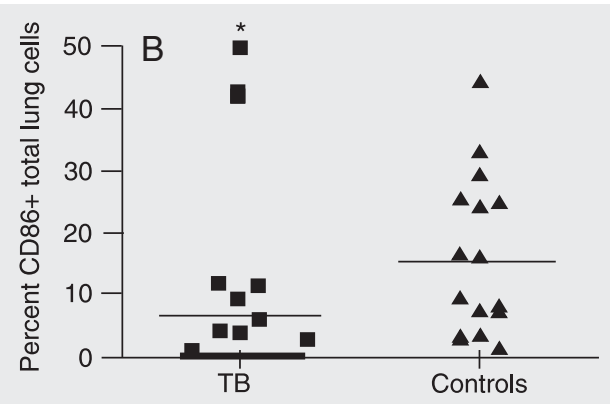

Figure 2. CD86 expression by total lung cells or macrophages from tuberculosis (TB) cases and non-TB controls. The horizontal lines are the means. The thick line over TB represents the individual results equal to zero. $A$, Percentage of macrophages expressing CD86. $B$, Percentage of total lung cells expressing CD86 cells from induced sputum were prepared from TB cases $(\mathrm{N}=22)$ and non-TB controls $(N=17)$. One result for the controls was equal to zero and is not shown. $C$, TB patients were segregated by extent of disease on chest $\mathrm{X}$-ray: limited $(<1$ lobe involvement) and extensive ( $>1$ lobe involvement). ${ }^{*} \mathrm{P}<0.05$ compared to controls in $A$ and $B$ and to limited disease in $C$ (Student $t$-test). 
study of lung inflammation and TB $(3,18$ $20)$. The application of this technique is a valuable strategy for the investigation of $\mathrm{TB}$ pathogenesis because of its safety, noninvasive nature, lower cost, and its ability to obtain sufficient viable lung cells from the diseased portion of the lung.

Human TB is amongst several diseases in which an altered balance in the Th1-type and Th2-type immune response is thought to foster active disease. Studies of the peripheral compartment of cells have found suppressed $\mathrm{T}$ cell proliferation, reduced IL-2 production, and impaired delayed type hypersensitivity reaction to the tuberculin skin test (4-6). Among the proposed contributory mechanisms to this down-modulated lung immune state is that $M$. tuberculosis antigens act either directly or via a paracrine effect by the promotion of excessive "antiinflammatory/down-modulatory" cytokines such as IL-10 that diminish antigen presentation and/or co-stimulation $(8,21,22)$. IL10 has been shown in vitro to diminish costimulatory and MHC class II molecule expression on peripheral blood immune cells $(8,12)$. Alternatively, excessive apoptosis of CD4+ T cells due to low expression of Bcl2 and excessive expression of TGF- $\beta$, Fas ligand, and TNF- $\alpha$ may further contribute to the immune dysregulation (23). Our previous study in the lung bridges the two concepts. First, we identified increased amounts of IL-10 and bioactive TGF- $\beta$, as well as increased co-expression of TGF- $\beta$ receptors I and II required for a cell response to TGF$B(2,3)$. Second, we noted in the lung of patients with active TB detectable levels of CFP32, an M. tuberculosis-specific antigen that positively correlated with amounts of IL-10 but not IFN- $\gamma$ (3). However, we did not examine in these patients whether expression of antigen presentation and costimulatory molecules were disturbed in active TB. Our present results revealed that active TB is associated with significantly lower expression of antigen presentation and co- stimulatory molecules, MHC class II HLADR and CD86. Both molecules (MHC class II and CD86) play pivotal roles in $\mathrm{T}$ cell activation and differentiation through the presentation of antigen peptides to $\mathrm{T}$ cell receptors and the concomitant co-stimulatory signaling $(7,24,25)$. Therefore, our data on lung immune cells during active TB provide the in vivo missing link for many in vitro mechanistic studies, in which attenuation of MHC class II expression by mononuclear phagocytes infected with virulent M. tuberculosis has been described in past years to involve several mechanisms $(26,27)$. M. tuberculosis molecules, such as $19-\mathrm{kDa}$ lipoprotein, antigen 85B and LpsG, interfere with the production of MHC class II molecules in the phagosomes of macrophages and dendritic cells $(21,28,29)$. The $19-\mathrm{kDa}$ lipoprotein was also shown to selectively inhibit IFN- $\gamma$-induced class transactivator expression to diminish MHC class II expression (30). Both IFN- $\gamma$ and IL-10 also play a role in MHC class II. Inhibition of IFN- $\gamma$ by up-regulation of histone deacetylation in the promoter region of the IFN- $\gamma$ gene leads to attenuation of MHC class II expression in $M$. tuberculosis-infected macrophage-like cells (31). M. tuberculosis-induced IL-10 secretion leads to inhibition of cathepsin S, resulting in lower export of peptide-loaded class II molecules to the cell surface and diminished antigen presentation (12). Furthermore, Chang et al. (32), using mathematical modeling, concluded that M. tuberculosis utilizes multiple mechanisms to interfere with antigen presentation, allowing a continuous inhibition of MHC class II antigen presentation to effector cells.

The growing numbers of pathways in the B7:CD28 family provide second signals to activate, inhibit, and fine-tune $\mathrm{T}$ cell responses (7,33-35). These distinct outcomes may occur in part by sequential CD80/CD86 interactions with either T cell CD28 or CTLA4 (full-length) (34), or may be conferred by whether the CD4+ $\mathrm{T}$ cell is in the resting or 
activated state (25). In murine TB, two studies correlated lower levels of CD86 expression with persistence of $M$. tuberculosis or disease progression $(22,36)$. Garcia-Romo et al. (37) found delayed expression of costimulatory molecules by dendritic cells in mice mediastinal lymph nodes after intratracheal infection by $M$. tuberculosis, leading to delayed adaptive immune responses and progression to disease in the lung. The present results found diminished CD86 expression in human lung cells and specifically in macrophages during active pulmonary TB. This is one of the earliest human in vivo results to confirm the prior reports on murine TB $(22,37)$. In one other study of costimulatory molecules in human TB, Soler et al. (38) failed to show differences in the expression of CD80/CD86 costimulatory molecules in tubercle granulomas caused by M. tuberculosis. This finding is in apparent contrast to our current findings. However, on close inspection, even though we observed an overall diminished CD86 expression by all cells, the most significant decrease was seen in patients with limited disease ( $\leq 1$ lobe). We interpret these findings to suggest that diminished CD86 expression occurs preferentially in earlier stages of clinical TB and might contribute to disease establishment and progression in the lungs.
Down-modulation of CD86 becomes less apparent with advanced disease or in contained infection, as in the case of the tubercle granuloma.

In conclusion, our ex vivo findings indicate that HLA-DR and CD86, key elements for antigen-specific $\mathrm{T}$ cell immune responses against $M$. tuberculosis, are diminished on the lung cells of pulmonary TB patients. Decreased expression of HLA-DR and CD86 on the surface of lung immune cells of TB patients might result from direct cell infection by $M$. tuberculosis or from a response to antigens released by $M$. tuberculosis, or may be indirectly mediated by immunosuppressive cytokines, IL-10 and/or TGF- $\beta$ promoted by $M$. tuberculosis. The diminished levels of HLA-DR and CD86 molecules on lung immune cells of TB patients may limit $\mathrm{T}$ cell immune responses that, in turn, favor M. tuberculosis persistence and progression to active disease.

\section{Acknowledgments}

The authors thank Dr. Richard D. Huard, Weill Medical College of Cornell University, NewYork, USA, for personal communication on the induction of IL-10 by human monocytes stimulated in vitro by CFP32.

\section{References}

1. http://www.who.int/tb/en. Accessed May 10, 2006.

2. Bonecini-Almeida MG, Ho JL, Boechat N, Huard RC, Chitale S, Doo $\mathrm{H}$, et al. Down-modulation of lung immune responses by interleukin10 and transforming growth factor beta (TGF-beta) and analysis of TGF-beta receptors I and II in active tuberculosis. Infect Immun 2004; 72: 2628-2634.

3. Huard RC, Chitale S, Leung M, Lazzarini LC, Zhu H, Shashkina E, et al. The Mycobacterium tuberculosis complex-restricted gene cfp32 encodes an expressed protein that is detectable in tuberculosis patients and is positively correlated with pulmonary interleukin-10. Infect Immun 2003; 71: 6871-6883.

4. Ellner JJ. Suppressor adherent cells in human tuberculosis. $J$ Immunol 1978; 121: 2573-2579.

5. Toossi Z, Kleinhenz ME, Ellner JJ. Defective interleukin 2 produc- tion and responsiveness in human pulmonary tuberculosis. $J$ Exp Med 1986; 163: 1162-1172.

6. Schauf V, Rom WN, Smith KA, Sampaio EP, Meyn PA, Tramontana $\mathrm{JM}$, et al. Cytokine gene activation and modified responsiveness to interleukin-2 in the blood of tuberculosis patients. J Infect Dis 1993; 168: 1056-1059.

7. Sharpe AH, Freeman GJ. The B7-CD28 superfamily. Nat Rev Immunol 2002; 2: 116-126.

8. de la Barrera S, Aleman M, Musella R, Schierloh P, Pasquinelli V, Garcia V, et al. IL-10 down-regulates costimulatory molecules on Mycobacterium tuberculosis-pulsed macrophages and impairs the lytic activity of CD4 and CD8 CTL in tuberculosis patients. Clin Exp Immunol 2004; 138: 128-138.

9. Palosaari H, Parisien JP, Rodriguez JJ, Ulane CM, Horvath CM. 
STAT protein interference and suppression of cytokine signal transduction by measles virus $V$ protein. J Virol 2003; 77: 7635-7644.

10. Murray PJ, Young RA. Increased antimycobacterial immunity in interleukin-10-deficient mice. Infect Immun 1999; 67: 3087-3095.

11. Hirsch CS, Hussain R, Toossi Z, Dawood G, Shahid F, Ellner JJ. Cross-modulation by transforming growth factor beta in human tuberculosis: suppression of antigen-driven blastogenesis and interferon gamma production. Proc Natl Acad Sci U S A 1996; 93: 31933198.

12. Pin I, Gibson PG, Kolendowicz R, Girgis-Gabardo A, Denburg JA, Hargreave FE, et al. Use of induced sputum cell counts to investigate airway inflammation in asthma. Thorax 1992; 47: 25-29.

13. American Thoracic Society/Centers for Disease Control and Prevention/Infectious Diseases Society of America: controlling tuberculosis in the United States. Am J Respir Crit Care Med 2005; 172 : 1169-1227.

14. Nicholson S, Bonecini-Almeida MG, Lapa e Silva JR, Nathan C, Xie $\mathrm{QW}$, Mumford R, et al. Inducible nitric oxide synthase in pulmonary alveolar macrophages from patients with tuberculosis. J Exp Med 1996; 183: 2293-2302.

15. Lapa e Silva JR, Linhares C, Boechat N, Rego L, Almeida MG, Kriski $\mathrm{AL}$, et al. Phenotypes of lung mononuclear phagocytes in HIV seronegative tuberculosis patients: evidence for new recruitment and cell activation. Mem Inst Oswaldo Cruz 1996; 91: 389-394.

16. Conde MB, Soares SL, Mello FC, Rezende VM, Almeida LL, Reingold $\mathrm{AL}$, et al. Comparison of sputum induction with fiberoptic bronchoscopy in the diagnosis of tuberculosis: experience at an acquired immune deficiency syndrome reference center in Rio de Janeiro, Brazil. Am J Respir Crit Care Med 2000; 162: 2238-2240.

17. Conde MB, Loivos AC, Rezende VM, Soares SL, Mello FC, Reingold $\mathrm{AL}$, et al. Yield of sputum induction in the diagnosis of pleural tuberculosis. Am J Respir Crit Care Med 2003; 167: 723-725.

18. Brightling CE. Clinical applications of induced sputum. Chest 2006; 129: 1344-1348.

19. Pavord ID, Pizzichini MM, Pizzichini E, Hargreave FE. The use of induced sputum to investigate airway inflammation. Thorax 1997; 52: 498-501.

20. Almeida A, Boechat N, Lago P, Flores-Batista V, Santos AR, Nociari $M$, et al. Analysis of immunomodulatory molecules in lung cells of tuberculosis patients before and after chemotherapy by RT-PCR. Proc Am Thorac Soc 2006; 3: 391.

21. Fulton SA, Reba SM, Pai RK, Pennini M, Torres M, Harding CV, et al. Inhibition of major histocompatibility complex II expression and antigen processing in murine alveolar macrophages by Mycobacterium bovis BCG and the 19-kilodalton mycobacterial lipoprotein. Infect Immun 2004; 72: 2101-2110.

22. Bonato VL, Medeiros Al, Lima VM, Dias AR, Faccioliti LH, Silva CL. Downmodulation of CD18 and CD86 on macrophages and VLA-4 on lymphocytes in experimental tuberculosis. Scand $J$ Immunol 2001; 54: 564-573.

23. Hirsch CS, Johnson JL, Okwera A, Kanost RA, Wu M, Peters P, et al. Mechanisms of apoptosis of T-cells in human tuberculosis. J Clin Immunol 2005; 25: 353-364.

24. Bhatia S, Edidin M, Almo SC, Nathenson SG. B7-1 and B7-2: similar costimulatory ligands with different biochemical, oligomeric and sig- naling properties. Immunol Lett 2006; 104: 70-75.

25. Rogers NJ, Game DS, Camara NO, Jackson IM, Lombardi G, Lechler RI. Distinct effects of CD86-mediated costimulation on resting versus activated human CD4+ T cells. Eur J Immunol 2005; 35: 2909-2919.

26. Hmama Z, Gabathuler R, Jefferies WA, de Jong G, Reiner NE. Attenuation of HLA-DR expression by mononuclear phagocytes infected with Mycobacterium tuberculosis is related to intracellular sequestration of immature class II heterodimers. J Immunol 1998; 161: $4882-4893$.

27. Noss EH, Harding CV, Boom WH. Mycobacterium tuberculosis inhibits MHC class II antigen processing in murine bone marrow macrophages. Cell Immunol 2000; 201: 63-74.

28. Ramachandra L, Noss E, Boom WH, Harding CV. Processing of Mycobacterium tuberculosis antigen 85B involves intraphagosomal formation of peptide-major histocompatibility complex II complexes and is inhibited by live bacilli that decrease phagosome maturation. $J$ Exp Med 2001; 194: 1421-1432.

29. Gehring AJ, Dobos KM, Belisle JT, Harding CV, Boom WH. Mycobacterium tuberculosis LprG (Rv1411c): a novel TLR-2 ligand that inhibits human macrophage class II MHC antigen processing. $J$ Immunol 2004; 173: 2660-2668.

30. Pai RK, Convery M, Hamilton TA, Boom WH, Harding CV. Inhibition of IFN-gamma-induced class II transactivator expression by a 19$\mathrm{kDa}$ lipoprotein from Mycobacterium tuberculosis: a potential mechanism for immune evasion. J Immunol 2003; 171: 175-184.

31. Wang Y, Curry HM, Zwilling BS, Lafuse WP. Mycobacteria inhibition of IFN-gamma induced HLA-DR gene expression by up-regulating histone deacetylation at the promoter region in human THP-1 monocytic cells. J Immunol 2005; 174: 5687-5694.

32. Chang ST, Linderman JJ, Kirschner DE. Multiple mechanisms allow Mycobacterium tuberculosis to continuously inhibit MHC class IImediated antigen presentation by macrophages. Proc Natl Acad Sci U S A 2005; 102: 4530-4535.

33. Greenwald RJ, Freeman GJ, Sharpe AH. The B7 family revisited. Annu Rev Immunol 2005; 23: 515-548.

34. Teft WA, Kirchhof MG, Madrenas J. A molecular perspective of CTLA-4 function. Annu Rev Immunol 2006; 24: 65-97.

35. Vijayakrishnan L, Slavik JM, Illes Z, Greenwald RJ, Rainbow D, Greve B, et al. An autoimmune disease-associated CTLA-4 splice variant lacking the $\mathrm{B} 7$ binding domain signals negatively in $\mathrm{T}$ cells. Immunity 2004; 20: 563-575.

36. Ordway D, Harton M, Henao-Tamayo M, Montoya R, Orme IM, Gonzalez-Juarrero M. Enhanced macrophage activity in granulomatous lesions of immune mice challenged with Mycobacterium tuberculosis. J Immunol 2006; 176: 4931-4939.

37. Garcia-Romo GS, Pedroza-Gonzalez A, Aguilar-Leon D, OrozcoEstevez H, Lambrecht BN, Estrada-Garcia I, et al. Airways infection with virulent Mycobacterium tuberculosis delays the influx of dendritic cells and the expression of costimulatory molecules in mediastinal lymph nodes. Immunology 2004; 112: 661-668.

38. Soler P, Boussaud V, Moreau J, Bergeron A, Bonnette P, Hance AJ, et al. In situ expression of B7 and CD40 costimulatory molecules by normal human lung macrophages and epithelioid cells in tuberculoid granulomas. Clin Exp Immunol 1999; 116: 332-339. 